\title{
Effects of basic fibroblast growth factor on density and morphology of fibroblasts grown on root surfaces with or without conditioning with tetracycline or EDTA
}

\author{
Karina G. Silvério, Aurora E. T. Martinez and Carlos Rossa Jr \\ Department of Diagnosis and Surgery, School of Dentistry at Araraquara, \\ São Paulo State University, SP, Brazil
}

(Received 6 March 2006 and accepted 25 June 2007)

\begin{abstract}
A study was conducted to evaluate in vitro the effect of root surface conditioning with basic fibroblast growth factor (b-FGF) on morphology and proliferation of fibroblasts. Three experimental groups were used: non-treated, and treated with $50 \mu$ g or 125 $\mu \mathrm{g}$ b-FGF/ml. The dentin samples in each group were divided into subgroups according to the chemical treatement received before application of b-FGF: none, or conditioned with tetracycline-HCl or EDTA. After contact with b-FGF for $5 \mathrm{~min}$, the samples were incubated for $24 \mathrm{~h}$ with $1 \mathrm{ml}$ of culture medium containing $1 \times 10^{5}$ cells $/ \mathrm{ml}$ plus $1 \mathrm{ml}$ of culture medium alone. The samples were then subjected to routine preparation for SEM, and random fields were photographed. Three calibrated and blind examiners peformed the assessment of morphology and density according to two index systems. Classification and regression trees indicated that the root surfaces treated with $125 \mu \mathrm{g}$ b-FGF and previously conditioned with tetracycline-HCl or EDTA presented a morphology more suggestive of cellular adhesion and viability $(P$ $=0.004)$. The density of fibroblasts on samples previously conditioned with EDTA, regardless of treatment with b-FGF, was significantly higher than in the other groups $(P<\mathbf{0 . 0 0 1})$. The present findings suggest that topical application of $b$-FGF has a positive influence on both the density and morphology of fibroblasts. (J. Oral Sci. 49, 213-220, 2007)
\end{abstract}

Correspondence to Dr. Carlos Rossa Junior, Department of Diagnosis and Surgery, School of Dentistry at Araraquara - UNESP, Rua Humaitá, 1680, Centro - Araraquara, SP, CEP 14801-903, Brasil

Tel: +55-16-3301-6369

Fax: +55-16-3301-6369

E-mail: crossajr@foar.unesp.br
Keywords: basic fibroblast growth factor; root conditioning; cell culture; fibroblasts.

\section{Introduction}

The ideal goal of periodontal therapy is to regenerate periodontal tissues that have been lost as a result of periodontal disease progression. Although periodontal regenerative therapies have generated much interest, details about the biological events involved and their control are still sparse. It is currently believed that stabilization of the blood clot within the wound followed by migration of periodontal ligament cells onto the root surface exposed by the disease process are crucial events in the process of periodontal regeneration (1-4).

Regenerative therapies rely extensively on the healing capacity of the host, since the use of grafts, implants or barrier membranes does not actively stimulate any biological processes. Growth factors are biological mediators that have received much attention recently because of their ability to actively regulate various cellular functions $(5,6)$. Basic fibroblast growth factor (b-FGF) is one such mediator capable of stimulating periodontal regeneration $(7,8)$. In vivo studies $(9,10)$ have demonstrated regeneration of mineralized (alveolar bone and root cementum) and non-mineralized (periodontal ligament) tissues in several types of bone defects treated with this growth factor. In vitro studies $(11,12)$ have verified the chemoattractant and proliferative effects of b-FGF when dentin slices are treated with this substance and used as a substrate for growing periodontal ligament cells.

One of the many issues associated with the use of growth factors is their usually short half-life. Some studies have demonstrated that pre-conditioning of root surfaces with demineralizing chemical agents leads to improved 
adsorption of the growth factor to the root surface, probably because of exposure of the dentin collagenous matrix $(11,13,14)$. It has also been shown that exposure of the collagenous matrix, per se, facilitates the migration and adhesion of periodontal ligament cells $(11,12,14)$.

The aim of the present study was to evaluate the influence of different concentrations of b-FGF on the density and morphology of fibroblastic cells grown on root surfaces with or without previous chemical conditioning with tetracycline or EDTA. It was anticipated that the data would provide support for the use of root conditioning prior to the application of growth factors in regenerative therapies.

\section{Materials and Methods}

\section{Sample selection}

A total of 50 anterior teeth extracted due to loss of function because of severe periodontal disease were collected from patients who were diagnosed as having chronic periodontitis and who were free of any systemic diseases that could affect the periodontal tissues. The study protocol was approved by the Research Ethics Comittee of the School of Dentistry at Araraquara - UNESP.

Sample preparation, sterilization and assignment

After extraction, teeth were rinsed and only the portion of the root exposed to the disease process was used to obtain dentin samples. Then, a single operator scaled the target portion of the root surface by performing 30 scaling strokes with a 5/6 Gracey curette (Neumar, São Paulo, SP, Brazil). The tooth crown was cut off $2 \mathrm{~mm}$ apical to the cementumenamel junction, the root was further sectioned longitudinally, and 4-mm dentin slices approximately $2 \mathrm{~mm}$ thick were obtained. A total of 90 specimens were prepared and autoclaved. These dentin slices were randomly divided into 3 experimental groups (30 specimens/group), according to the type of chemical pre-conditioning performed: control (non-conditioned), TTC (tetracycline- $\mathrm{HCl}$ conditioned samples) and EDTA (24\% neutral EDTA conditioned samples). Each group was further divided into three subgroups according to the concentration of the growth factor employed: control (no b-FGF), $50 \mu \mathrm{g} / \mathrm{ml}$ or $125 \mu \mathrm{g} / \mathrm{ml}$ b-FGF.

\section{Preparation of test solutions (TTC, EDTA and b-FGF)}

TTC-HCl was prepared by slow dissolution of the tetracyline $\mathrm{HCl}$ salt (Santa Paula, Drugstore, Araraquara, Brazil) in sterile deionized water to a final concentration of $50 \mathrm{mg} / \mathrm{ml}$. EDTA at 24\% (Santa Paula) was used in a gel formulation directly as supplied by the manufacturer.
Basic fibroblast growth factor (Sigma, St Louis, MO, USA) was diluted immediately before use in Eagle Minimum Essential Medium (MEM, Cultilab, Campinas, SP, Brazil) supplemented with $7.5 \%$ fetal bovine serum (Adolf Lutz Institute, São Paulo, SP, Brazil) and $40 \mu \mathrm{g} / \mathrm{ml}$ gentamicin (Schering Plough, Rio de Janeiro, RJ, Brazil) to concentrations of 50 and $125 \mu \mathrm{g} / \mathrm{ml}$.

\section{Treatment of the specimens}

Control group specimens were only scaled and root planed. In the TTC group, the dentin slices were conditioned with TTC-HCL ( $50 \mathrm{mg} / \mathrm{ml}$ ) applied for $3 \mathrm{~min}$ with cotton pellets that were substituted every $30 \mathrm{sec}$. Similarly, in the EDTA group the specimens were conditioned with EDTA $24 \%$ ( $\mathrm{pH} 7.0$ ) for $3 \mathrm{~min}$. All specimens were rinsed with $10 \mathrm{ml}$ of PBS buffer, pH 7.4 (Invitrogen Corp., Carlsbad, CA, USA) and subsequently immersed in FBS-free MEM with or without b-FGF at each tested concentration for 5 $\min$.

\section{Cell culture}

McCoy cells (Adolf Lutz Institute), a continuous lineage of fibroblastic cells, were used in this study. The cells were grown on MEM supplemented with $40 \mu \mathrm{g} / \mathrm{ml}$ gentamicin and $7.5 \%$ fetal bovine serum, and maintained in an atmosphere of $98 \%$ humidity, $5 \% \mathrm{CO}_{2}$ and $37^{\circ} \mathrm{C}$. Culture maintenance and all experiments were performed using disposable plastic cell culture plates. Preliminary RT-PCR experiments demonstrated expression of $\alpha 2$-integrin, $\beta 1$ integrin and type I collagen mRNA by the McCoy cells (data not shown). The dentin slices were initially subjected to chemical treatment and subsequently immersed in FBSfree medium with or without b-FGF. These dentin slices were then transferred to 24-well cell culture plates (Corning, New York, NY, USA) and $2 \mathrm{ml}$ of MEM with $2.5 \times 10^{4}$ cells were added to each well. After a 24-h incubation, the medium was removed by aspiration, and the specimens were gently washed with $2 \mathrm{ml}$ of PBS and fixed by immersion in $2.5 \%$ glutaraldehyde (Sigma, St Louis, MO, USA) for $15 \mathrm{~min}$. Initial dehydration was performed by placing the specimens in increasing concentrations of ethanol $(10 \%, 30 \%, 50 \%, 70 \%, 90 \%$ and $100 \%, 15 \mathrm{~min}$ at each concentration). After $24 \mathrm{~h}$ at room temperature, the specimens were fixed to metal stubs and placed in a vacuum desiccator (Pyrex Labware-Corning, San Nicolas, Mexico) for 3 days. After sputter-coating with gold (200 $\mathrm{nm}$ thickness), the specimens were observed in a scanning electron microscope (JEOL JSM-T330A, Tokyo, Japan). Three micrographs were obtained at $\times 500$ in random areas of the central portion of each specimen by a microscope technician, who was unaware of the experimental group 
coding or the purpose of the study. One of these fields was randomly chosen to be photographed at $\times 1,000$ magnification.

\section{Data collection and analysis}

Three independent examiners, calibrated and blind to the experimental group coding, assessed fibroblast density using the index described by Jenkins et al. (15) also modified by us: $0=$ no cells or only occasional cells, $1=$ presence of some cells without confluence, $2=$ partial cellular confluence and 3 = a confluent layer of cells covering the entire specimen surface. The same examiners evaluated fibroblast morphology using the $\times 1,000$ micrographs according to the index system proposed by Gamal et al. (13) and modified by us: $0=$ no cells, $1=$ rounded cells, $2=$ flattened cells and $3=$ combination of rounded and flattened cells. Calibration within examiners indicated a $99 \%$ accuracy, whereas among the examiners the kappa was always greater than 0.8 .

Significant influences of root conditioning and b-FGF concentration on cell density and morphology were evaluated using Classification and Regression Trees (16) using the statistical package Statistica for Windows, v5.1 (Statsoft Inc., Tulsa, OK, USA).

\section{Results}

The data on cell density were dichotomized into two categories because of the distribution of the scores: 1sparse cells without confluence and 2-cells with partial or complete confluence. Application of the classification tree to the density data initially indicated a significant influence of the chemical conditioning performed prior to b-FGF exposure, a greater density being observed after EDTA conditioning, followed by the control group. Tetracycline conditioning gave the worst results in terms of cell density (Fig. 1).

Within each group, the concentrations of b-FGF used had a significant influence on cell density. In the EDTA group, no b-FGF or the lower concentration $(50 \mu \mathrm{g} / \mathrm{ml})$ yielded the best results, whereas the higher concentration of b-FGF $(125 \mu \mathrm{g} / \mathrm{ml})$ decreased cell density on the EDTAconditioned samples. On the other hand, b-FGF had a compensatory effect on the negative impact of tetracycline conditioning, since either concentration of b-FGF increased

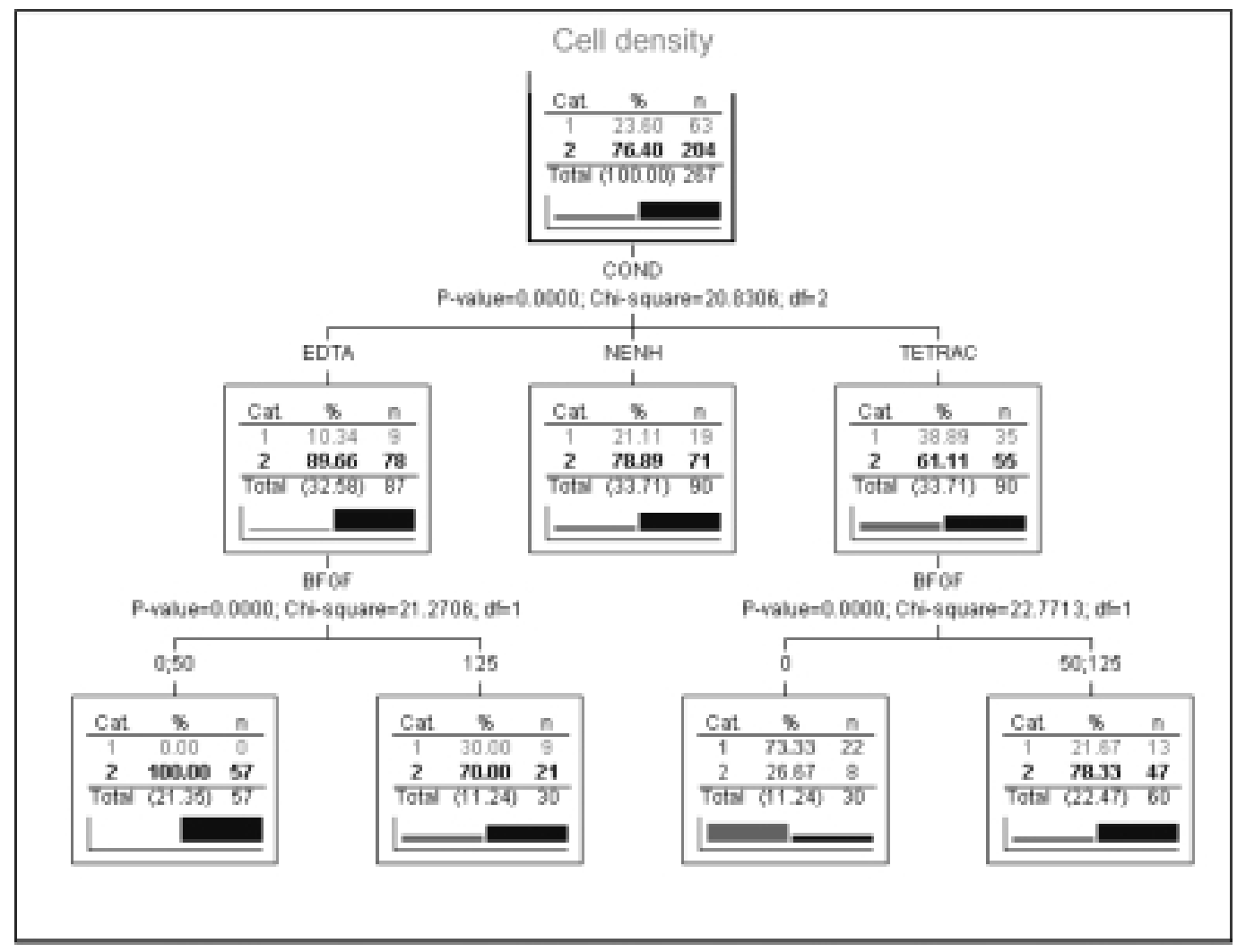

Fig. 1 Classification and Regression Tree analysis applied to dichotomized fibroblast cell density categories. Even though most samples (76.4\%) showed partial or complete cell confluence (category 2, top of the tree), the analysis indicated significant influence of chemical pre-conditioning with EDTA, yielding a higher proportion of samples showing complete or partial confluence of cells ( $89.6 \%$ ), followed by no conditioning ('NENH', with $78.9 \%$ ) and tetracycline (61.1\%). Within each group, b-FGF treatment increased cell density in the tetracycline- $\mathrm{HCl}$ conditioned group, whereas the higher concentration of b-FGF decreased the cell density of EDTA-conditioned samples. 
the cell density significantly. The fact that exposure to bFGF had no significant effect on cell density on the specimens that did not receive any form of previous chemical conditioning indicated that adsorption of the growth factor on unconditioned dentin surfaces might have been reduced or impaired. Moreover, it is important to note that the cell density on the control unconditioned specimens was usually higher than that on the specimens pre-conditioned with tetracycline, but somewhat lower than that on specimens pre-conditioned with EDTA.

Dichotomization was also performed for the data on cell morphology, since categories ' 0 ' (no cells) and ' 1 ' (rounded cells) were not observed in any of the specimens. The classification tree indicated initially that cell morphology was significantly influenced by exposure to b-FGF, represented by an increase in the prevalence of score 3 (combination of rounded and flattened cells) except for EDTA-conditioned samples, in which b-FGF reduced the proportion of score 3 .

Interestingly, in the specimens that were not exposed to b-FGF, the prevalent score indicated flattened cells. However, conditioning with EDTA resulted in a greater prevalence of mixed rounded and flattened cells, as opposed to either control (no conditioning) or TTC-HCl conditioning. On the other hand, exposure to b-FGF was associated with a dose-response effect in non-conditioned and TTC-HCl-conditioned samples, a greater prevalence of score 3 being observed with $125 \mu \mathrm{g} / \mathrm{ml}$ than with 50 $\mu \mathrm{g} / \mathrm{ml}$. (Fig. 2). This, in contrast with the cell density results, suggested that even without any chemical pre-

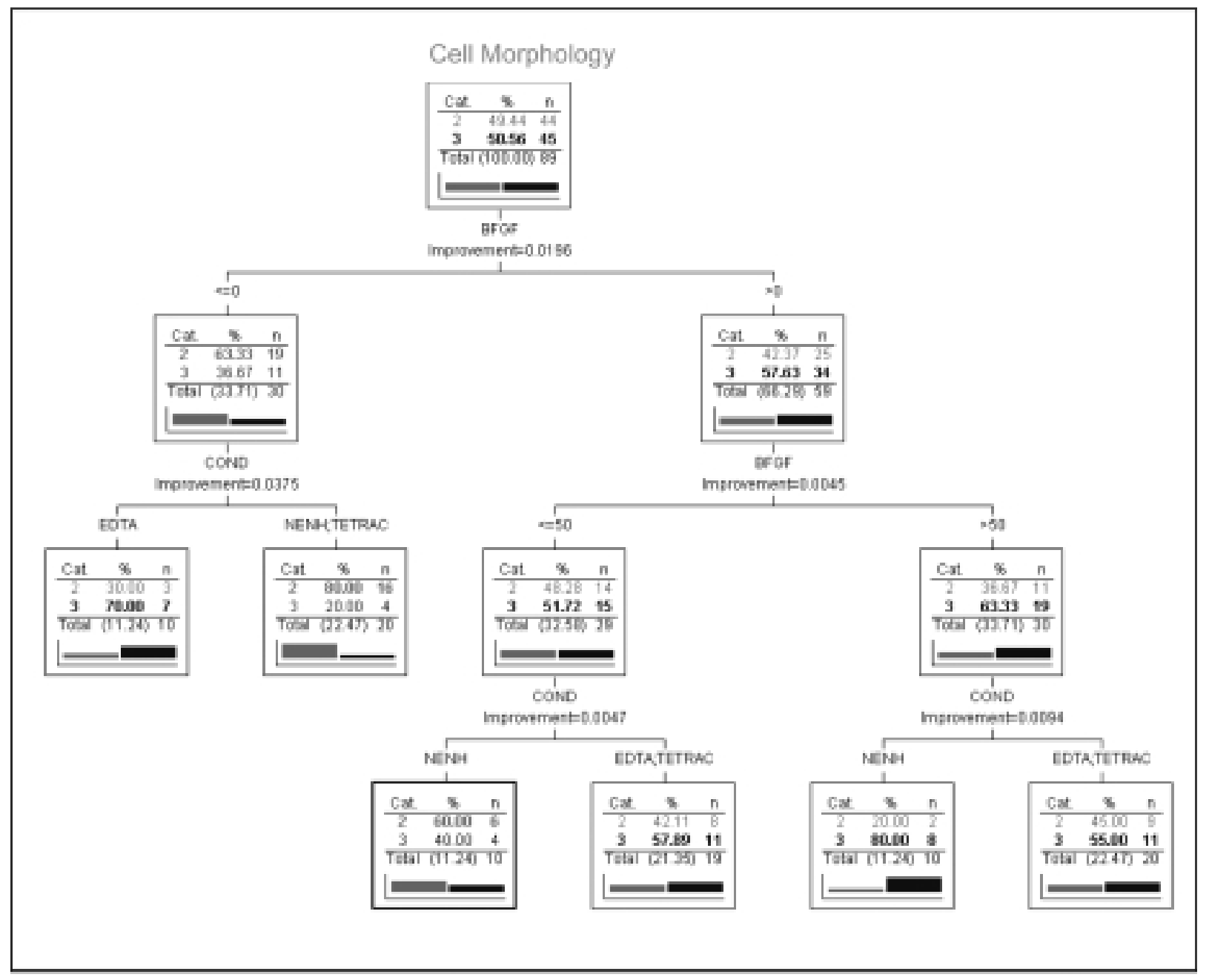

Fig. 2 Classification and Regression Tree analysis applied to dichotomized fibroblast cell morphology categories. In contrast to the results for density, the main effect on cell morphology was observed with b-FGF treatment, which resulted in a higher proportion of mixed rounded and flattened cells (57.6\% of samples in comparison to only $36.7 \%$ of samples classified in category 3 with and without b-FGF, respectively). There was a dose-dependent effect of b-FGF on cell morphology, since higher concentrations yielded a greater proportion of category 3 samples. Among the samples that were not exposed to b-FGF, chemical pre-conditioning with EDTA significantly increased the proportion of category 3 samples in comparison to both non-conditioned ('NENH') and tetracycline- $\mathrm{HCl}$ conditioned samples. 
conditioning of the dentin slices, b-FGF did exert an effect. Interestingly, this effect was negative in EDTA-conditioned samples.

Figures 3 (A - D) and 4 (A - C) show representative images of the main findings on cell density and morphology, respectively. In the dentin slices of the tetracycline group, the majority of the photomicrographs $(73.33 \%)$ of specimens not exposed to b-FGF showed some cells but no confluence, while most samples $(78.33 \%)$ treated with 50 or $125 \mu \mathrm{g} / \mathrm{ml}$ b-FGF had an increased degree of cellular confluence. These influences of b-FGF on cellular density were not observed in the specimens that did not receive any chemical pre-conditioning (control group), most specimens $(78.89 \%)$ showing a confluent layer of cells. EDTA-conditioned specimens tended to show a higher cell density. On the other hand, morphology was affected primarily by exposure to b-FGF, since most specimens presented a combination of rounded and flattened cells, as opposed to mostly flattened cells in the absence of bFGF. With regard to specimens not exposed to b-FGF, differences in cell morphology were evident in accordance with the type of chemical treatment: $70 \%$ of EDTAconditioned specimens presented a combination of rounded and flattened cells, whereas $80 \%$ of tetracycline-conditioned and control specimens showed only flattened cells.

\section{Discussion}

The purpose of this study was to evaluate the effect of b-FGF on fibroblast morphology and density using a design that attempted to simulate the clinical setting in which this growth factor is used for periodontal regenerative procedures. EDTA and tetracycline- $\mathrm{HCl}$ were used as pretreatment to study the effect of dentin pre-conditioning on the effects of b-FGF. The density of cells present on the dentin slices was used as an indirect assessment of cell adhesion/proliferation, and morphology assessment was used as an indirect indicator of cell adhesion and viability, since fibroblasts that are viable and effectively attached to the substrate present a bipolar or multipolar morphology, instead of a rounded one (13).

The results demonstrated that application of either of the concentrations of b-FGF (50 or $125 \mu \mathrm{g} / \mathrm{ml}$ ) promoted an increase in cellular density (partial or total cellular confluence) of the samples previously conditioned with TTC-HCl. Terranova and Wikesjö (12) observed an increase in the chemotaxis of PDL cells after treatment of TTC/HCl-
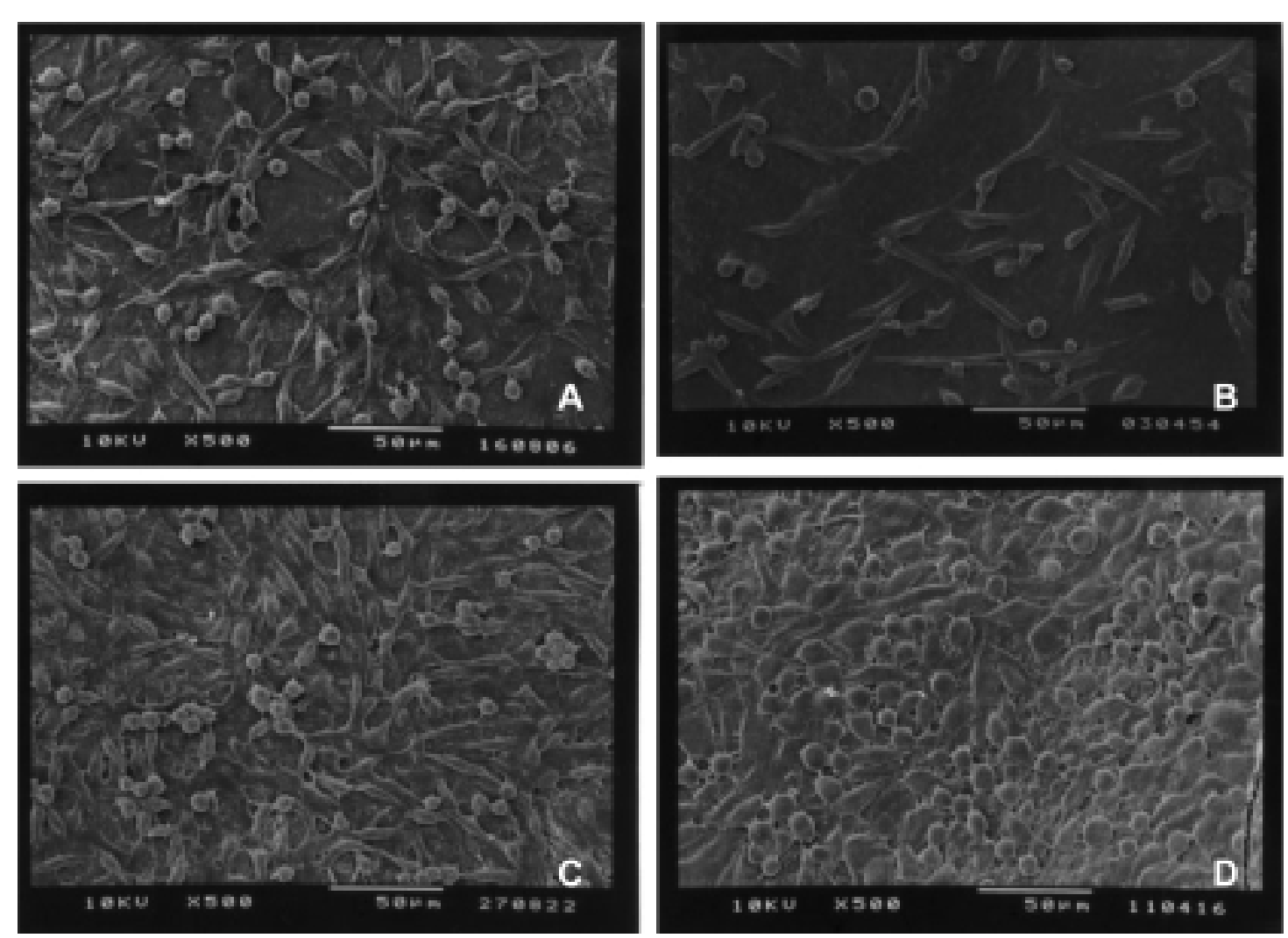

Fig. 3 Panel of representative photomicrographs for analysis of cell density. Tetracycline-HCl-conditioned samples showed only sparse cells (B), whereas treatment with either concentration of b-FGF increased cell density $(\mathrm{C}$, treated with $50 \mu \mathrm{g} / \mathrm{ml}$ b-FGF). Both non-conditioned (D) and EDTA-conditioned (A) samples showed higher cell density, without any positive effect of exposure to b-FGF. Bar $=50 \mu \mathrm{m}$ (original magnification $\times 500$ ). 

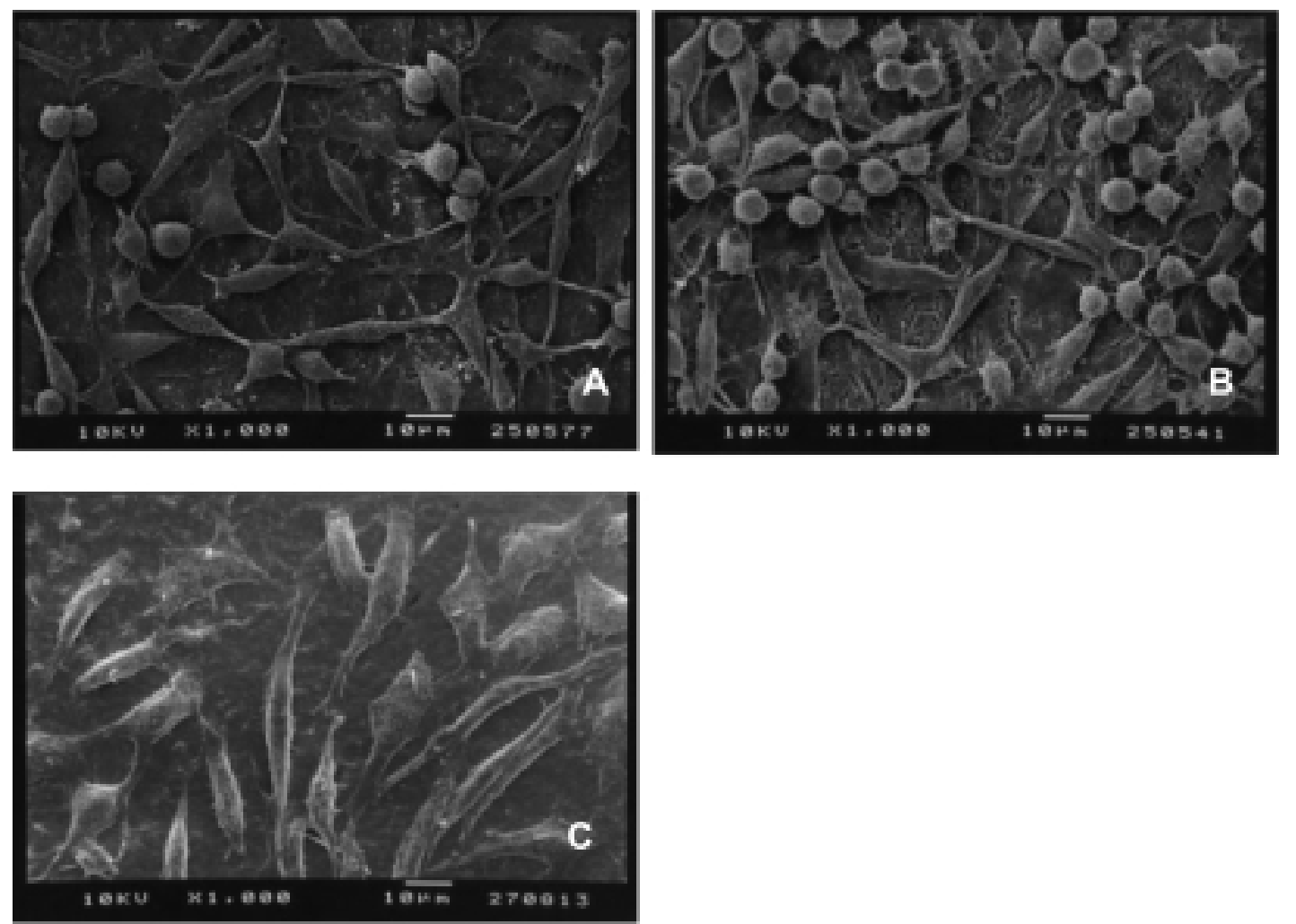

Fig. 4 Panel of representative photomicrographs for analysis of cell morphology. Non-conditioned samples showed only flattened cells (C), whereas treatment with b-FGF changed the morphology to a mixture of rounded and flattened cells in a dosedependent manner (A, treated with $50 \mu \mathrm{g} / \mathrm{ml}$ b-FGF; B, treated with $125 \mu \mathrm{g} / \mathrm{ml}$ b-FGF). Tetracycline-HCl-conditioned samples were influenced similarly, whereas exposure of EDTA-conditioned samples to b-FGF resulted in a diminished proportion of category 3 scores (not shown). Bar $=50 \mu \mathrm{m}$ (original magnification $\times 1,000$ ).

conditioned dentin specimens with b-FGF. Furthermore, Terranova et al. (11) related the increase in the cellular density to the adsorption of b-FGF onto dentin specimens previously treated with tetracycline hydrochloride.

However, this increase in cellular density after treatment with b-FGF was not observed in the group treated with EDTA, although this group presented partial or total cellular confluence on most of the samples. It is likely that the differences in the chemical behavior of TTC- $\mathrm{HCl}$ and EDTA influenced these results. Even though both substances cause superficial demineralization of dentine, resulting in exposure of collagen fibers that would facilitate binding of b-FGF and cellular proliferation (14), there is evidence suggesting that low-pH etching agents, such as TTC-HCl, can alter the structure of the collagen fibers, decreasing cellular adhesion (17-20). The results of the present study suggest that treatment with b-FGF may compensate for this negative effect caused by low-pH tetracycline by increasing cellular density.

In contrast, 24\% EDTA at neutral $\mathrm{pH}$ reportedly sequesters calcium from hydroxyapatite, leaving the collagen fiber structure intact $(21,22)$. This may have favored cell migration and attachment to the dentin specimens. Nevertheless, application of b-FGF to dentin specimens previously treated with EDTA did not increase fibroblast density. It is likely that synergistic effects between EDTA and b-FGF did not occur because of chemical incompatibility between these substances. Other speculative possibilities include the capacity of EDTA to denature b-FGF, and the possibility that EDTA may interfere with the cellular receptors specific to this growth factor on fibroblasts.

In relation to cellular morphology, treatment of dentin specimens with b-FGF appeared to produce a combination of round and flat cells, while the majority of the specimens without application of b-FGF showed only flat cells on their surfaces. According to Gamal et al. (13), flat cells are firmly attached to the substratum by numerous attachment extensions and lamellipodia, while rounded cells are considered to be either poorly attached or to have recently divided by mitosis.

Careful observation of the photomicrographs showed that most of the rounded cells had lamellopodia, suggesting transformation to a flat shape, while a few others were 
clearly undergoing mitosis, which is indicative of cellular health rather than cell death. Thus, the association of both types of cellular morphology in this study can be considered to be more indicative of increased cell proliferation in comparison with the presence of predominantly flattened cells, because dividing cells usually become rounded during mitosis. Although subjective, this assumption suggests that treatment with b-FGF, especially at a concentration of $125 \mu \mathrm{g} / \mathrm{ml}$, induced a more pronounced proliferative response, since it led more frequently to a combination of round and flat cells, independently of the previous chemical conditioning.

On the other hand, most of the specimens in the group treated with $50 \mu \mathrm{g} / \mathrm{ml}$ b-FGF presented only flattened cells. Even so, the cellular density of specimens treated with $50 \mu \mathrm{g} / \mathrm{ml}$ b-FGF was not different from that of the specimens treated with $125 \mu \mathrm{g} / \mathrm{ml} \mathrm{b-FGF,} \mathrm{thus} \mathrm{casting}$ doubt on the supposed 'beneficial' influence of the higher concentration of b-FGF on cellular density, represented by a greater number of round (and possibly dividing) cells. These apparently conflicting results may be a consequence of the reduced growth factor application time (5 min) or reduced observation time $(24 \mathrm{~h})$ in this experiment.

This possible effect of $\mathrm{b}-\mathrm{FGF}$ on cell proliferation represented by modification of cell morphology is supported by the finding that specimens conditioned with EDTA but not treated with b-FGF showed cells with flattened morphology. Probably, in these specimens, chemotaxis and attachment of fibroblasts were stimulated, but not their proliferation.

The control group specimens treated with TTC-HCl showed a lower cell density and more rounded cells in comparison with the control group treated with EDTA. It is conceivable that the characteristics of this chemical agent, including low $\mathrm{pH}$, binding to dentin following topical application, and release from the dentin surface in active form for at least $48 \mathrm{~h}$ (18), may have altered the culture medium, impairing fibroblast proliferation and/or adhesion.

Additionally, some other factors related to the methodology of the present study, such as cell lineage, method and time of application of $b-F G F$, and preparation of the samples for SEM, may have influenced the results obtained. Even considering all the limitations of the methods we employed, it is suggested that topical application of b-FGF had a positive influence on both the density and morphology of fibroblasts.

We conclude that pre-conditioning of root surfaces with $24 \%$ EDTA at neutral $\mathrm{pH}$ yielded the best results in terms of cell density/adhesion than either no conditioning or TTC-HCl. b-FGF treatment of EDTA-conditioned samples not only failed to improve the results, but in fact - at the higher concentration - decreased the cell density. Topical exposure of root surfaces to b-FGF affected cell morphology regardless of chemical pre-conditioning. Nevertheless, the clinical use of growth factors in periodontal regenerative therapy depends on knowing the role of each growth factor in the process of periodontal tissue repair, as well as the ideal concentration and method of application of these substances. It is hoped that in vitro analysis of cell behavior in the presence of various growth factors will help to clarify their in vivo mechanisms of action, ultimately leading to safe and predictable clinical use of such growth factors for periodontal regenerative therapy.

\section{Acknowledgments}

CAPES-PROAP Foundation of Brazilian Ministry of Education and FAPESP grant \#00/14270-0 for financial support.

\section{References}

1. Bartold PM, Raben A (1996) Growth factor modulation of fibroblasts in simulated wound healing. J Periodontal Res 31, 205-216

2. Melcher AH (1976) On the repair potential of periodontal tissues. J Periodontol 47, 256-260

3. Nyman S, Gottlow J, Karring T, Lindhe J (1982) The regenerative potential of the periodontal ligament. An experimental study in the monkey. J Clin Periodontol 9, 257-265

4. Nyman S, Karring T, Lindhe J, Plantén S (1980) Healing following implantation of periodontitisaffected roots into gingival connective tissue. J Clin Periodontol 7, 394-401

5. Callens A (1997) Growth factors in periodontal regeneration - a review. In Proceedings of the 2 nd European workshop on periodontology, Lang NP, Karring T, Lindhe J eds, Quintessence, Berlin, 284302

6. Graves DT, Cochran DL (1994) Periodontal regeneration with polypeptide growth factors. Curr Opin Periodontol 2,178-186

7. Takayama S, Murakami S, Miki Y, Ikezawa K, Tasaka S, Terashima A, Asano T, Okada H (1997) Effects of basic fibroblast growth factor on human periodontal ligament cells. J Periodontal Res 32, 667675

8. Takayama S, Murakami S, Nozaki T, Ikezawa K, Miki Y, Asano T, Terashima A, Okada H (1998) Expression of receptors for basic fibroblast growth factor on human periodontal ligament cells. J Periodontal Res 33, 315-322 
9. Murakami S, Takayama S, Ikesawa K, Shimabukuro Y, Kitamura M, Nozaki T, Terashima A, Asano T, Okada H (1999) Regeneration of periodontal tissues by basic fibroblast growth factor. J Periodontal Res $34,425-430$

10. Rossa C Jr, Marcantonio E Jr, Cirelli JA, Marcantonio RAC, Spolidorio LC, Fogo JC (2000) Regeneration of Class III furcation defects with basic fibroblast growth factor (b-FGF) associated with GTR. A descriptive and histometric study in dogs. J Periodontol 71, 775-784

11. Terranova VP, Odziemiec C, Tweden KS, Spadone DP (1989) Repopulation of dentin surfaces by periodontal ligament cells and endothelial cells. Effect of basic fibroblast growth factor. J Periodontol 60, 293-301

12. Terranova VP, Wikesjö UME (1988) Chemotaxis of cells isolated from periodontal tissues to different biological response modifiers. Adv Dent Res 2, 215-222

13. Gamal AY, Mailhot JM, Garnick JJ, Newhouse R, Sharawy MM (1998) Human periodontal ligament fibroblast response to PDGF-BB and IGF-1 application on tetracycline $\mathrm{HCl}$ conditioned root surfaces. J Clin Periodontol 25, 404-412

14. Terranova VP, Franzetti LC, Hic S, DiFlorio RM, Lyall RM, Wikesjö UME, Baker PJ, Christersson LA, Genco RJ (1986) A biochemical approach to periodontal regeneration: tetracycline treatment of dentin promotes fibroblast adhesion and growth. J Periodontal Res 21, 330-337
15. Jenkins S, Addy M, Wade W (1988) The mechanism of action of chlorhexidine. A study of plaque growth on enamel inserts in vivo. J Clin Periodontol 15, 415424

16. Breiman L, Friedman J, Stone CJ, Olshen RA (1984) Classification and regression trees. Chapman \& Hall, New York, 103-148

17. Blomlöf J, Lindskog S (1995) Root surface texture and early cell and tissue colonization after different etching modalities. Eur J Oral Sci 103, 17-24

18. Frantz B, Polson A (1988) Tissue interactions with dentin specimens after demineralization using tetracycline. J Periodontol 59, 714-721

19. Sterrett JD, Simmons J, Whitford G, Russell CM (1997) Tetracycline demineralization of dentin: the effects of concentration and application time. J Clin Periodontol 24, 457-463

20. Zaman KU, Sugaya T, Hongo O, Kato H (2000) A study of attached and oriented human periodontal ligament cells to periodontally diseased cementum and dentin after demineralizing with neutral and low pH etching solution. J Periodontol 71, 1094-1099

21. Blomlöf JPS, Blomlöf LB, Lindskog SF (1997) Smear layer formed by different root planing modalities and its removal by an ethylenediaminetetraacetic acid gel preparation. Int J Periodontics Restorative Dent 17, 242-249

22. Blomlöf J (1996) Root cementum apperance in healthy monkeys and periodontitis-prone patients after different etching modalities. J Clin Periodontol $23,12-18$ 